\title{
Respiratory system, lung, and chest wall mechanics after longitudinal laparotomy in rats
}

\author{
L.F.P. Moreira, S.T. Aires, C.F. Gobbi, P.H.N. Saldiva, W.A. Zin
}

Respiratory system, lung, and chest wall mechanics after longitudinal laparotomy in rats. L.F.P. Moreira, S.T. Aires, C.F. Gobbi, P.H.N. Saldiva, W.A. Zin. (CERS Journals Ltd 1995.

ABSTRACT: It has been demonstrated that respiratory resistance and elastance increase whilst the abdomen remains open during longitudinal laparotomy. We wished to determine whether changes also occur after abdominal closure in the same animal preparation.

In 10 sedated, anaesthetized paralysed, and mechanically-ventilated rats $(309 \pm 33$ (SD) g), resistances and elastances of the respiratory system, lung, and chest wall were measured both before longitudinal laparotomy and directly after abdominal closure. Furthermore, the resistances were also split into their initial and difference components, the former reflecting the Newtonian resistances and the latter representing the viscoelastic/inhomogeneous pressure dissipations in the system. For this purpose, the end inflation occlusion during constant inspiratory flow method was used.

After laparotomy, no statistically significant changes were found in elastances and resistances of the respiratory system, lungs and chest wall (paired Student's t-test, significance level $=5 \%$ ).

It can be concluded that after midline xiphipubic laparotomy accompanied by bilateral ventro-dorsal infracostal incision, respiratory resistances and elastances were not different from those found in the control condition.

Eur Respir J., 1995, 8, 105-108

Laparotomy often leads to respiratory impairment postoperatively. Several potential mechanisms may be suggested to explain muscular dysfunction after this surgery [1-3]. However, postoperative respiratory mechanical changes are not well understood. It has recently been demonstrated in guinea-pigs and rats $[4,5]$ that, during longitudinal laparotomy, respiratory system elastance increases because of its lung and chest wall components. Respiratory system resistance was also found to increase whilst the abdomen remained open $[4,5]$, as a result higher mechanical inhomogeneities and/or viscoelastic properties of the chest wall [4]. Furthermore, although pulmonary contribution to respiratory system inhomogeneities/viscoelasticity is quite well understood [6-8], the relative contributions of the rib cage and abdomen components to those properties have only recently received much attention [6-13]. Hence, in the present investigation, the previous studies using the laparotomy model $[4,5]$ have been extended to verify the hypothesis that closure of the laparotomic cut could normalize lung and chest wall mechanics.

\section{Methods}

Ten adult Wistar rats (weight $230-355 \mathrm{~g}$; mean $309 \pm 33$ (SD) g) were initially sedated with diazepam (5 mg i.p.),
Instituto de Biofisica Carlos Chagas Filho, UFRJ, Ilha do Fundão, Rio de Janeiro, Laboratório de Poluição Atmosférica Experimental, and Instituto do Coração, FMUSP, SP, Brazil.

Correspondence: W.A. Zin, Universidade Federal do Rio de Janeiro, Instituto de Biofisica Carlos Chagas Filho, Centro de Ciencias da Saúde, Ilha do Fundão, 21949900 - Rio de Janeiro - RJ, Brazil

Keywords: Elastance, rat, resistance, surgery, viscoelasticity

Received: November 41993

Accepted after revision September 211994

This study was supported by the following Brazilian agencies: Brazilian Council for Scientific and Technological Development (CNPq), Financing for Studies and Projects (FINEP), Graduate Teaching and Research Council of the Federal University of Rio de Janeiro (CEPG-UFRJ), São Paulo State Research Supporting Foundation (FAPESP), and Laboratories of Medical Investigation (LIM-FMUSP). and anaesthetized with pentobarbital sodium $\left(20 \mathrm{mg} \cdot \mathrm{kg}^{-1}\right.$ i.p.). A snugly fitting cannula (1.5 $\mathrm{mm}$ internal diameter (ID)) was introduced into the trachea under direct vision aided by a small laryngoscope. The rats were then placed in the supine position on a heated surgical table.

An adequate pneumotachograph [14] was connected to the tracheal cannula for the measurements of airflow (V) and, by electronic integration, of tidal volume (V). The flow resistance of the equipment (tracheal cannula included) (Req), was constant up to flow rates of $26 \mathrm{ml} \cdot \mathrm{s}^{-1}$ and amounted to $0.03 \mathrm{cmH}_{2} \mathrm{O} \cdot \mathrm{ml}^{-1} \cdot \mathrm{s}$. Because abrupt changes of diameter were not present in our circuit, errors of measurement of flow resistance were avoided $[15,16]$. The equipment dead space was $0.4 \mathrm{ml}$. Tracheal pressure (Ptr) was measured with a Hewlett Packard 270 differential pressure transducer. Changes in oesophageal pressure (Poes) were measured with a $30 \mathrm{~cm}$ long water-filled catheter (PE-240), with side holes at the tip connected to a PR23-2D-300 Statham differential pressure transducer. The catheter was passed into the stomach and then slowly returned into the oesophagus; its proper positioning was assessed using the "occlusion test" [17]. The Ptr signal was then connected to the other port of the transducer so that changes in transpulmonary pressure $\left(\mathrm{P}_{\mathrm{L}}=\mathrm{Ptr}\right.$-Poes) were, thereafter, registered.

The rats were then paralysed with succinylcholine 
chloride (5 mg.kg i.p.) and artificially ventilated with a constant flow ventilator. During the measurement periods, an end-inspiratory pause could be generated by adjusting the ventilator settings. In order to avoid the effects of different flows and tidal volumes, and thence inspiratory duration, on the measured variables $[7,8,18]$, special care was taken to keep tidal volume (VT) and flow constant in all animals. The experiments lasted no more than 45 min.

The frequency responses of the pressure measurement systems (Ptr and $\mathrm{PL}$ ) were flat up to $20 \mathrm{~Hz}$, without appreciable phase shift between the signals. All signals were conditioned and amplified in a Beckman type $\mathrm{R}$ Dynograph and recorded on paper at speeds of 1 and 5 $\mathrm{mm} \cdot \mathrm{s}^{-1}$. The signals were also passed through 8 pole Bessel filters (902LPF, Frequency Devices) with their corner frequencies set at $100 \mathrm{~Hz}$. They were then sampled at $200 \mathrm{~Hz}$ with a 12-bit analogue-to-digital converter (DT-2801A, Data Translation) and stored on computer. All data were collected using LABDAT software (RHTInfoData).

The measurements were performed before incision and immediately after abdominal closure. The abdominal anterior wall was cut at the midline in the craniocaudal direction, and at the sides in the ventrodorsal direction caudad to the rib cage. In addition, in order to assess possible modifications in diaphragmatic resting position, the rats underwent radioscopic examination before incision and immediately after abdominal closure.

Respiratory mechanics were measured from endinspiratory occlusions after constant flow inflations [19]. Although this method has been used for a long time, the significance of the measured variables has only recently been clarified [6, 8, 19-22]. After end-inspiratory occlusion, there is a fast initial drop in $\operatorname{Ptr}(\Delta$ Pinit,rs) from the preocclusion value up to an inflection point $(\mathrm{Pi}, \mathrm{rs})$ followed by a slower pressure drop ( $\triangle$ Pdiff,rs) to a plateau. This plateau corresponds to the elastic recoil pressure of the respiratory system (Pel,rs). $\Delta$ Pinit,rs and $\Delta$ Pdiff,rs divided by the flow immediately preceding the occlusion provide the initial, or viscous, (Rvis,rs) and difference (Rdiff,rs) resistances of the respiratory system, respectively. Rvis,rs selectively reflects the combination of airway and chest wall Newtonian resistances in normal animals [6, 18, 21]. Rdiff,rs, with the units of resistance, reflects stress relaxation of the lung and chest wall tissues, together with a tiny contribution of pendelluft in normal situations $[6,7,23] . \Delta$ Pinit,rs $+\Delta$ Pdiff,rs divided by flow gives the total respiratory system resistance (Rtot,rs). The same procedures apply to PL, yielding the values of total (Rtot,L), initial (Rvis,L), and difference (Rdiff,L) resistance of the lung. Total (Rtot,w), initial (Rvis,w), and difference (Rdiff,w) resistances of the chest wall were calculated by subtracting the pulmonary from the corresponding respiratory system values. Req was subtracted from Rtot,rs, Rtot,L, Rvis,rs, and Rvis,L, so that the results reported here represent intrinsic resistance values. Respiratory system and lung elastances (Est,rs and Est,L, respectively) were calculated by dividing the corresponding elastic recoil pressures (Pel,rs and Pel,L, respectively) by VT. Chest wall elastance (Est,w) was calculated by subtracting Est,L from Est,rs. Five to 10 determinations were performed in each animal, before and after surgery. Before each data collection period the airway contents were aspirated to remove possible mucus collection and the respiratory system was inflated to total lung capacity $\left(\mathrm{Ptr}=+30 \mathrm{cmH}_{2} \mathrm{O}\right)$. The manoeuvre was repeated three times.

Because a mechanical occlusion valve always takes a finite time to close, $F$ neyer drops to zero immediately upon interruption. The $F$ passing through the valve as it shuts increases the pressures, and may, thus, lead to an underestimation of Rtot and Rvis [7, 24]. The closing time of the valve used in the ventilator within the experimental range of inspiratory flows was $7 \mathrm{~ms}$. The delay was allowed for by back-extrapolation of the pressure records to the actual time of occlusion and the corrections in resistance, although very minute, were performed as described previously [7].

All data were analysed using ANADAT data analysis software (RHT-InfoData).

Statistical analysis was performed by means of the Student's paired t-test, with the significance level established at $5 \%$.

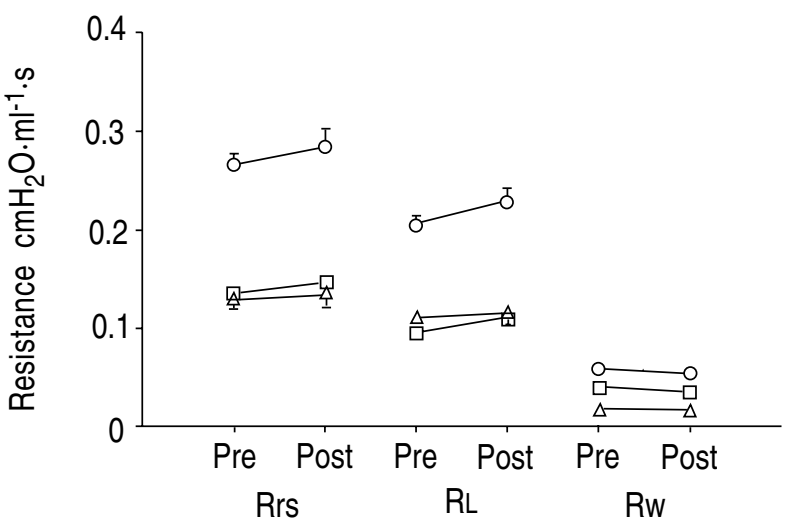

Fig. 1. - Respiratory system (Rrs), lung (RL), and chest wall (Rw) resistances before surgery (Pre) and after abdominal closure (Post). Values are means +/- SEM of seven rats. $O$ : total resistance (Rtot); $\Delta \quad \Delta$ : initial resistance (Rvis); $\square-\square$ : difference resistance (Rdiff). In all instances, no statistically significant difference could be detected.

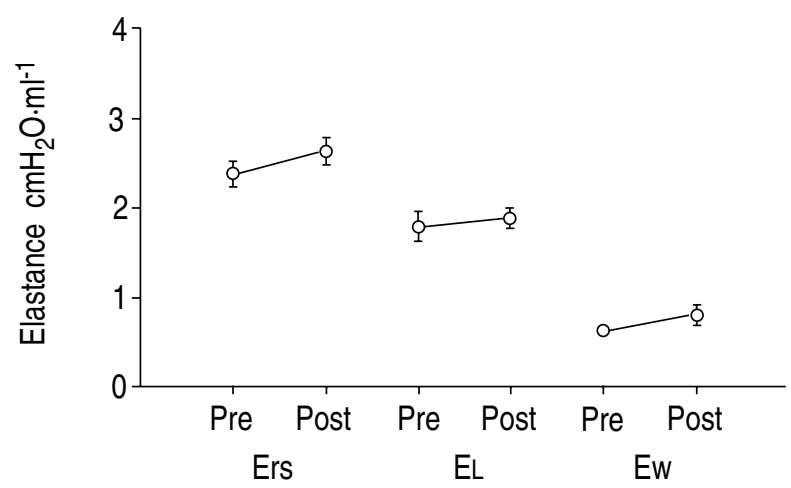

Fig. 2. - Respiratory system (Ers), lung (EL), and chest wall (Ew) static elastances before surgery (Pre) and after abdominal closure (Post). Values are means $+/$ - SEM of seven rats. In all instances no statistically significant difference could be detected. 


\section{Results}

Mean constant inspiratory flows $( \pm \mathrm{SD})$ measured before and after surgery amounted to $8.96 \pm 0.46$ and $9.18 \pm 0.61$ $\mathrm{ml} \cdot \mathrm{s}^{-1}$, respectively. The corresponding tidal volumes were $2.30 \pm 0.16$ and $2.28 \pm 0.16 \mathrm{ml}$. No statistically significant difference could be detected.

Although a tendency to find higher respiratory system and lung resistances after abdominal closure could be noted (fig. 1), these changes were not statistically significant. The same applied to lung, chest wall, and respiratory system elastances (fig. 2).

\section{Discussion}

It is well known that, after laparotomy, respiratory dysfunction often occurs [25, 26], and pain [1], residual effects of anaesthetics and muscle relaxants [1], diaphragmatic fatigue [2], and neural reflexes [3] have been claimed to be responsible for it. Recently, studies in rats and guinea-pigs demonstrated that there are also mechanical factors leading to respiratory impairment while the abdomen remains open $[4,5]$. However, the mechanical effects of longitudinal laparotomy have not so far been studied directly after abdominal closure.

As previously reported in rats [5] and guinea-pigs [4], the change in functional residual capacity (FRC) after abdominal opening was negligible, consisting of an expired volume not more than $0.1 \mathrm{ml}$. It could, thus, be assumed that in the present study no changes in FRC occurred, since the experiments were performed under similar conditions. Supporting this hypothesis, no difference in diaphragmatic resting position could be detected by radioscopic examination performed before and after surgery.

In spontaneously breathing dogs, it has been shown that, after longitudinal abdominal opening, there is a decrease in tidal volume accompanied by higher integrated inspiratory muscular electrical activity at the 2 nd and 6th intercostal spaces [27]. It could be speculated that this finding is secondary to an increased mechanical impedance in the respiratory system. As already demonstrated in anaesthetized paralysed mechanicallyventilated rats [5], wide longitudinal laparotomy induced a significant increase in Rtot,rs due to a rise in Rdiff,rs. In a complementary study in guinea-pigs [4], Rdiff,rs was shown to increase following similar changes in Rdiff,w. Rdiff,w can be closely related to stress relaxation or stress recovery properties of the chest wall tissues, together with a tiny contribution of asynchrony of movement within and between the chest wall components [2, $6,23]$.

It is conceivable that after abdominal opening, changes in chest wall tissue viscoelastic properties are inclined to occur. In fact, the chest wall is made up of heterogeneous tissues: the rib cage consists primarily of the complex lever and joint system of the ribs, sternum, spinal column, and various muscle groups; the diaphragmabdomen is composed of muscles of the abdominal wall, abdominal contents, and diaphragm. Some of these elements are modified by wide abdominal opening, whereas the remaining ones undergo a new pattern of movement from their relaxed configuration to tidal volume [5]. In the present investigation, no significant changes in respiratory resistance could be identified (fig. 1). It seems that the factor (or factors) leading to increased Rdiff, w whilst the abdomen remained open, was circumvented by abdominal closure.

In rodents, longitudinal abdominal incision increased Est,rs, and Est,w [4, 5], diminished the lower rib cage circumference [5], and a cephalad diaphragmatic movement was observed $[4,5]$. Thus, it can be concluded that the stretched diaphragm could have become less compliant. The conformational changes of the rib cage could also, possibly, account for an increased Est,w. However, after abdominal closure, no statistically significant changes in elastance could be detected (fig. 2). It thus seems that abdominal wall suture restored chest wall mechanical integrity.

In conclusion, respiratory system, lung, and chest wall resistance and elastance remained unchanged after wide longitudinal laparotomy. These findings are important when considering the increased impedance of the system found whilst the abdomen remained open [4, 5, 27]. Moreover, they eliminate mechanical factors, as measured immediately after abdominal closure, as possible candidates for the respiratory impairment commonly found after wide laparotomy.

Acknowledgements: The authors are grateful to A. Carlos de Souza Quaresma for his skillful technical assistance.

\section{References}

1. Craig DB. Postoperative recovery of pulmonary function. Anesth Analg 1981; 60: 46-52.

2. Aubier M, DeTroyer A, Sampson M, Macklem PT, Roussos C. Aminophylline improves diaphragmatic contractility. N Engl J Med 1981; 305: 249-252.

3. Duron P. Intercostal and diaphragmatic muscle endings and afferents. In: Hornbein TF, ed. Regulation of Breathing. New York, Dekker, 1981; pp. 473-540.

4. Santos RLB, Santos MAM, Sakae RS, Saldiva PHN, Zin WA. Effects of longitudinal laparotomy on respiratory system, lung, and chest wall mechanics. J Appl Physiol 1992; 72: 1985-1990.

5. Zin WA, Martins MA, Silva PRM, Sakae RS, Carvalho ALI, Saldiva PHN. Effects of abdominal opening on respiratory system mechanics in ventilated rats. J Appl Physiol 1989; 66: 2496-2501.

6. Bates JHT, Ludwig MS, Sly PD, Brown K, Martin JG, Fredberg JJ. Interrupter resistance elucidated by alveolar pressure measurements in open-chest normal dogs. $J$ Appl Physiol 1988; 65: 408-414.

7. Kochi T, Okubo S, Zin WA, Milic-Emili J. Flow and volume dependence of pulmonary mechanics in anesthetized cats. J Appl Physiol 1988; 64: 441-450.

8. Similowski T, Levy P, Corbeil C, et al. Viscoelastic behavior of lung and chest wall in dogs determined by flow interruption. J Appl Physiol 1989; 67: 2219-2229.

9. Barnas GM, Yoshino K, Fredberg J, Kikuchi Y, Loring $\mathrm{SH}$, Mead J. Total and local impedances of the chest wall up to $10 \mathrm{~Hz}$. J Appl Physiol 1990; 68: 1409-414. 
10. Barnas GM, Yoshino K, Loring SH, Mead J. Impedance and relative displacements; of related chest wall up to 4 Hz. J Appl Physiol 1987; 62: 71-81.

11. Barnas GM, Mills PJ, Mackenzie CF, et al. Regional chest wall impedance during nonrespiratory maneuvers. J Appl Physiol 1991; 70: 92-96.

12. Barnas GM, Stamenovic D, Fredberg JJ. Proportionality between chest wall resistance and elastance. J Appl Physiol 1991; 70: 511-515.

13. Rodrigues ACM, Moreira LFP, Souza CL, Pettersen PCD, Saldiva PHN, Zin WA. Effects of thoracotomy on respiratory system, lung, and chest wall mechanics. Chest 1993; 104: 1882-1886.

14. Mortola JP, Noworaj A. Two sidearm tracheal cannula for respiratory airflow measurements in small animals. J Appl Physiol: Respirat Environ Exercise Physiol 1987; 55: 250-253.

15. Chang HK, Mortola JP. Fluid dynamics factors in tracheal pressure measurements. J Appl Physiol: Respirat Environ Exercise Physiol 1981; 51: 218-225.

16. Loring SH, Elliot EA, Drazen JM. Kinetic energy loss and convective acceleration in respiratory resistance measurements. Lung 1979; 156: 33-42.

17. Baydur A, Behrakis PK, Zin WA, Jaeger M, Milic-Emili J. A simple method for assessing the validity of the esophageal balloon technique. Am Rev Respir Dis 1982; 126: 788-791.

18. Kochi T, Okubo S, Zin WA, Milic-Emili J. Chest wall and respiratory system mechanics in cats: effects of flow and volume. J Appl Physiol 1988; 64: 26362646.

19. Bates JHT, Rossi A, Milic-Emili J. Analysis of the behavior of the respiratory system with constant inspiratory flow. J Appl Physiol 1935; 58: 1840-1848.

20. Bates JHT, Baconnier P, Milic-Emili J. A theoretical analysis of the interrupter technique for measuring respiratory mechanics. J Appl Pysiol 1988; 64: 22042214.

21. Bates JHT, Brown KA, Kochi T. Respiratory mechanics in the normal dog determined by expiratory flow interruption. J Appl Physiol 1989; 67: 2276-2285.

22. Saldiva PHN, Zin WA, Santos RLB, Eidelman DH, MilicEmili J. Alveolar pressure measurement in open-chest rats. J Appl Physiol 1992; 72: 302-306

23. D'Angelo E, Calderini E, Torri G, Robatto FM, Bono D, Milic-Emili J. Respiratory mechanics in anesthetized paralyzed humans: effects of flow, volume and time. $J$ Appl Physiol 1989; 67: 2556-2564.

24. Bates JHT, Hunter I, Sly PD, Okubo S, Filiatrault S, Milic-Emili J. The effect of closure time on the determination of respiratory resistance by flow interruption. Med Biol Eng Comput 1987; 25: 136-140.

25. Hamilton WK, McDonald JS, Fischer HW, Bethards R. Postoperative respiratory complications. Anesthesiology 1964; 25: 607-612.

26. Latimer RG, Dickman M, Day WC, Gunn ML, Schmidt CD. Ventilatory patterns and pulmonary complications after upper abdominal surgery determined by preoperative and postoperative computerized spirometry and blood gas analysis. Am J Surg 1971; 122: 622-632.

27. Kelly S, Zin WA, Decramer M, DeTroyer A. Salutary effect of fall in abdominal pressure during diaphragm paralysis. J Appl Physiol: Respirat Environ Exercise Physiol 1984; 56: 1320-1324. 